\title{
The Concept of the Entrepreneurial University Applied to Universities of Technology in Austria: Already Reality or a Vision of the Future?
}

\author{
Martin Sperrer, Christiana Müller, and Julia Soos
}

\author{
"The biggest risk is not taking any risk..." \\ In a world that is changing really quickly, \\ the only strategy that is guaranteed to fail \\ is not taking risks.
}

Mark Zuckerberg

Founder of Facebook

\begin{abstract}
The concept of the "entrepreneurial university" is now recognized as a major driver for self-development and innovation and as an appropriate response to succeeding in highly turbulent and unpredictable markets. This article outlines and evaluates the current implementation of this concept at the universities of technology (TU) in Austria. First, to evaluate the status quo, a review of existing programs and initiatives was undertaken at the three universities comprising the "TU Austria": TU Graz, TU Wien (Vienna), and MU Leoben. Second, a questionnaire was designed on the basis of the HEInnovate framework and sent to representatives of the three universities and resulted in responses from TU Graz and TU Wien. The results underscore that the model of the entrepreneurial university represents the next step of development in higher education. Moreover, it demonstrates that there is still room for improvement at the TU Austria, especially in terms of fostering an entrepreneurial spirit among students.
\end{abstract}

\section{Introduction}

The idea of launching a startup company has surely crossed every person's mind at least once: becoming an entrepreneur promises personal fulfillment, interesting challenges, as well as financial success... if you are lucky. In Austria alone, 37,120 startup companies were founded in the year 2014 (BMWFM, 2015). Although this number seems to be high, the entrepreneurial activity in Austria is still low compared to "entrepreneurial countries" such as the United States (Singer et al., 2014). Especially from technical degree programs, only very few alumni decide to become entrepreneurs. This might be due to the lack of programs in the field of entrepreneurial education. The European Commission (2008), however, claims that it is technical and creative students that would benefit most from an entrepreneurial education. The European Commission goes even one step further and states that most of the innovative and useable ideas are coming from non-business studies (European Commission, 2008). In order to foster innovation and entrepreneurship across Europe, they created the European Institute of Innovation and Technology (EIT) in 2008. Within knowledge and innovation communities (KICs), the EIT brings together diverse partners (e.g., universities, research labs, companies) to develop innovative products and services, found companies, and so on (EIT, 2016). The universities of the TU Austria (tuaustria.ac.at/en/) participated in this initiative and were either coordinating a knowledge and innovation community or were partners in one. For example, TU Graz was coordinating a knowledge and innovation community focusing on sustainable energy and climate change mitigation, whereas both TU Wien and Montan University Leoben were partners in one focusing on raw materials. Another valuable network is the Conference of European Schools for Advanced Engineering Education and Research (CESAER; cesaer.org) - a nonprofit association of leading European universities with the goal to foster excellence in engineering education and research and innovations through close cooperations with industry. 


\title{
The Concept of the Entrepreneurial University in Austria
}

\author{
Martin Sperrer, Christiana Müller, and Julia Soos
}

The model of the "entrepreneurial university" is currently recognized by experts as a major driver for selfdevelopment and innovation and as an appropriate response to succeeding in highly turbulent and unpredictable markets (Hannon, 2013). Consequently, the question arises: should the topic of "entrepreneurship" be reinforced in higher education? To answer this question, this article examines the current implementation of the concept of the entrepreneurial university at the TU Austria. Furthermore, it investigates possible improvements of the existing entrepreneurial approaches. The respective research questions that this investigation addresses are:

\section{- How is the concept of the entrepreneurial university defined and who are the stakeholders of this concept?}

\section{- Is TU Austria already entrepreneurial?}

\section{- In which way(s) could the implementation of the entre- preneurial university be improved in the TU Austria?}

The investigation highlights the essential points about the discussion on the entrepreneurial university and provides a list of tools for entrepreneurial approaches. As far as existing entrepreneurial approaches in higher education in Austria are concerned, this article presents and discusses the results of a status-quo investigation among the TU Austria universities. Based on the collected information, it evaluates the current situation and offers specific recommendations for improvement. Future students (including potential entrepreneurs), as well as the academic and administrative staff of the TU Austria universities, stand to benefit the most from this study because it focuses on these institutions, but the general findings will also be of interest to equivalent stakeholders outside Austria. Therefore, this article is of interest to all universities that would like to understand how to become an entrepreneurial university and how to overcome implementation obstacles.

\section{Literature Review: The Concept of the Entrepreneurial University}

Researchers generally agree on the high potential of entrepreneurial universities in today's highly turbulent and unpredictable markets (Hannon, 2013). However, there are critics who doubt that the technical sector is the right place to implement an entrepreneurial university because the concept includes numerous elements of business education and it influences the autonomy of the universities (Krimsky et al., 1991). In addition, the model corresponds to an image of perfection that everyone wants to achieve but few know how to implement. The entrepreneurial university is a multifaceted process of continuous improvement; therefore, it is also difficult to define strict guidelines for its implementation (OECD, 2012). Given that the diversity of entrepreneurial approaches taken by universities is one of the concept's most important features (Fayolle \& Redford, 2015), a clear definition would be likely unachievable. However, for the purpose of our investigation, it was necessary to identify the salient features of the concept. The European guiding framework for entrepreneurial universities, called "HEInnovate", is published by the OECD and the European Commission and includes the most important features for self-assessment of higher-education institutions (OECD, 2012).

Despite the lack of a clear definition, the literature distinguishes between the entrepreneurial university, which is a concept that affects all parts of higher education, and "entrepreneurial education". The latter term is applied at all levels of education and could be seen as a component or tool of the entrepreneurial university. Also, within an entrepreneurial university, two important actors need to be distinguished: the academic entrepreneur and the entrepreneurial academic (Alexander et al., 2015). Academic entrepreneurs are academics that engage "in formal commercialization activities which often result in patent creation, license sales and or the creation of new ventures and spin out firms". In contrast, entrepreneurial academics participate in a wider range of activities that link the university with other organizations, particularly in industry. Thus, the entrepreneurial university is not just a new version of business programs with the aim to launch startups. It is more like an attitude that opens new possibilities for students as well as faculty members. Certainly, these are not the only groups who benefit from this model; there are many different stakeholders (see Box 1). The motivation of entrepreneurial academics plays a particularly important role in connecting different stakeholders.

Although we have some idea of the key features of the entrepreneurial university, what is lacking is knowledge of the best ways to develop and implement new programs. There is also a lack of information regarding Austria, where only a few studies (e.g., Daxner \& Kailer, 2009) consider the current national situation and, to our knowledge, none specifically reference the concept in relation to Austrian universities of technology. 


\title{
The Concept of the Entrepreneurial University in Austria
}

\author{
Martin Sperrer, Christiana Müller, and Julia Soos
}

\author{
Box 1. Stakeholder trends reflecting a shift toward the \\ entrepreneurial university (cf. Gibb \& Haskins, 2014) \\ Traditional stakeholders/funders \\ - research funders \\ - public higher education funding bodies \\ - central government \\ - peer assessment groups \\ Emerging dominant stakeholders \\ - students \\ - parents \\ - councils and boards \\ - schools and colleges \\ Increasingly prominent stakeholders \\ - alumni \\ - international agencies \\ - development agencies \\ - local government and community \\ - associations/non-governmental organizations \\ - academic institutions \\ - media \\ - business
}

In Austria, as elsewhere, different types of institutions provide entrepreneurial education. Austrian universities, for instance, have worked hard to become more entrepreneurial and have recently started to include the concept of the entrepreneurial university in their strategies. Nevertheless, entrepreneurship at the TU Austria is still in the early stages of development, and Austria generally lags behind other countries in establishing entrepreneurial approaches in higher education. For example, concerning the technical field in Europe, the University of Twente in the Netherlands has a long entrepreneurial history and has come very close to what we would consider an entrepreneurial university. Therefore, we undertook intensive research into the programs offered by the University of Twente in order to collect proven concepts.

Outside of Europe, the Massachusetts Institute of Technology (MIT) is an example of best practice in implementing the entrepreneurial university concept. The Martin Trust Center for MIT Entrepreneurship was founded in 1990 and offers more than 60 courses on a variety of topics. MIT follows a team-based approach with the focus on problem solving and a close connection with companies. The success is reflected in the numbers: in the first decade of the 2000s, MIT alumni started about 12,000 new firms and 18,000 are projected for the current decade. (Roberts et al., 2015) The success of MIT's entrepreneurial activities is a combination of several factors, such as excellent interdisciplinary research and research in practical fields, a strong network that includes ties to government and industry or the commitment to entrepreneurship programs (O'Shea et al., 2007).

\section{Stakeholders of the entrepreneurial university}

Following the famous triple helix model from Etzkowitz and colleagues (2008), the interest groups of the entrepreneurial university can be condensed to three key stakeholder categories: university, industry, and government. However, as can be seen in Box 1, the stakeholders are as multifaceted as the entrepreneurial university itself. Key stakeholders include, for example, the local government and the community, which can bring substantial benefits to the entrepreneurial university. It has been shown that entrepreneurs mostly take action in the region they have studied and, as a consequence, the local area can experience a boom (Kulicke \& Görisch, 2003). Therefore, locals should be very interested in implementing this model. And that is just one example: benefits like this can be found for all kinds of stakeholders. Current students as well as internal university stakeholders such as faculty members also benefit from and contribute to the entrepreneurial university. Professors can act as mentors for startups and may also realize their own ideas in cooperation with their students. Within an entrepreneurial university, close relationships are established with companies, which help ensure that students receive an up-to-date and relevant education. Nevertheless, some companies may view new academic ventures as potential competitors and might prefer to limit the roles of universities to research and consulting services (Etzkowitz et al., 2000). However, this outdated view is completely contrary to the concept of the entrepreneurial university and would restrict economic progress.

\section{The HEInnovate framework}

One of the essential parts of the questionnaire consists of the HEInnovate framework, which also concentrates on higher education (HE). This self-assessment tool for implementing the model of the entrepreneurial university was developed by the European Commission and the OECD to support higher education. Using this tool, a university can rate itself on a scale ranging from 0 (very weak) to 10 (very strong) in the following seven areas (European Commission, 2011): 


\section{The Concept of the Entrepreneurial University in Austria}

\section{Martin Sperrer, Christiana Müller, and Julia Soos}

\section{Leadership and governance}

2. Organizational capacity, people, and incentives

3. Entrepreneurship development in teaching and learning

\section{Pathways for entrepreneurs}

5. University-business/external relationships for knowledge exchange

6. The entrepreneurial university as an internationalized institution

7. Measuring the impact of the entrepreneurial university

For our questionnaire, we were able to adopt the framework without needing to tailor it to the Austrian context by using the detailed specifications as offered by the framework.

\section{Methodology}

Our studied involved four main steps:

1. First, we clarified how the multifaceted entrepreneurial university is defined in the context of Austrian universities of technology. To do this, we conducted a detailed review of the relevant literature based on recommendations and online searches using the keywords "entrepreneurial education", "entrepreneurial university", and "stakeholders of the entrepreneurial university", as well as each keyword in the context of TU Austria, TU Wien, TU Graz, and MU Leoben.

2. Next, we examined current practices to improve access to entrepreneurship for students and academic staff of Austrian universities of technology. By reviewing online information provided by the universities, we were able to create mind-maps of TU Graz, TU Wien, and MU Leoben that showed their programs and relationships with other institutions. Afterwards, we used the mindmaps and our literature review to create a list of relevant questions to include in a questionnaire customized to each university. The following questions were posed:

-When was the first time that students/employees of your university were confronted with the topic of "entrepreneurship"?
- To what extent (percentage) are students and employees aware of programs known that support entrepreneurship?

- Currently, there is a trend of becoming an "entrepreneurial university". What does your university do to meet this model?

3. In the third step, we presented a customized questionnaire - including the mind-map, HEInnovate framework, and additional questions - to a contact person at each university. Each person completing the questionnaire held the same or a comparable position (i.e., head of an institution) at their university and was familiar with their university's strategy. We also ensured that the respondent was already familiar with the relevant concepts of the entrepreneurial university and technology transfer.

4. Finally, we received and analyzed the responses from the representatives of TU Graz and TU Wien, including any gaps that were identified in the mindmaps. Unfortunately, the representative of MU Leoben did not provide a completed questionnaire.

\section{Results}

The results provide insights into what is actually being done in terms of implementing the concept of the entrepreneurial university in two universities of technology in Austria. Table 1 provides an overview of the self-assessment provided by the representatives of TU Graz and TU Wien. Notably, these results show strong similarities in the answers relating to the HEInnovate framework.

One of the few differences appeared in the first segment, which asks whether entrepreneurship is a major part of the university strategy. In the point system of the HEInnovate framework, which ranges from 0 (very bad) to 10 (very good), the TU Wien gave itself an 8 for this segment, whereas TU Graz gave itself a 4 . Nevertheless, despite TU Graz giving itself such a low score, we identified several points within the TU Graz strategy that align with the characteristics of an entrepreneurial university. And, regarding their commitment to implementing the model of the entrepreneurial university, both universities give themselves a high ranking.

Concerning faculty autonomy, both universities placed themselves in the lower half of the scale. Here, the university representatives see room for improvement. 


\section{The Concept of the Entrepreneurial University in Austria}

\section{Martin Sperrer, Christiana Müller, and Julia Soos}

Table 1. Overview of current practice at TU Graz and TU Wien

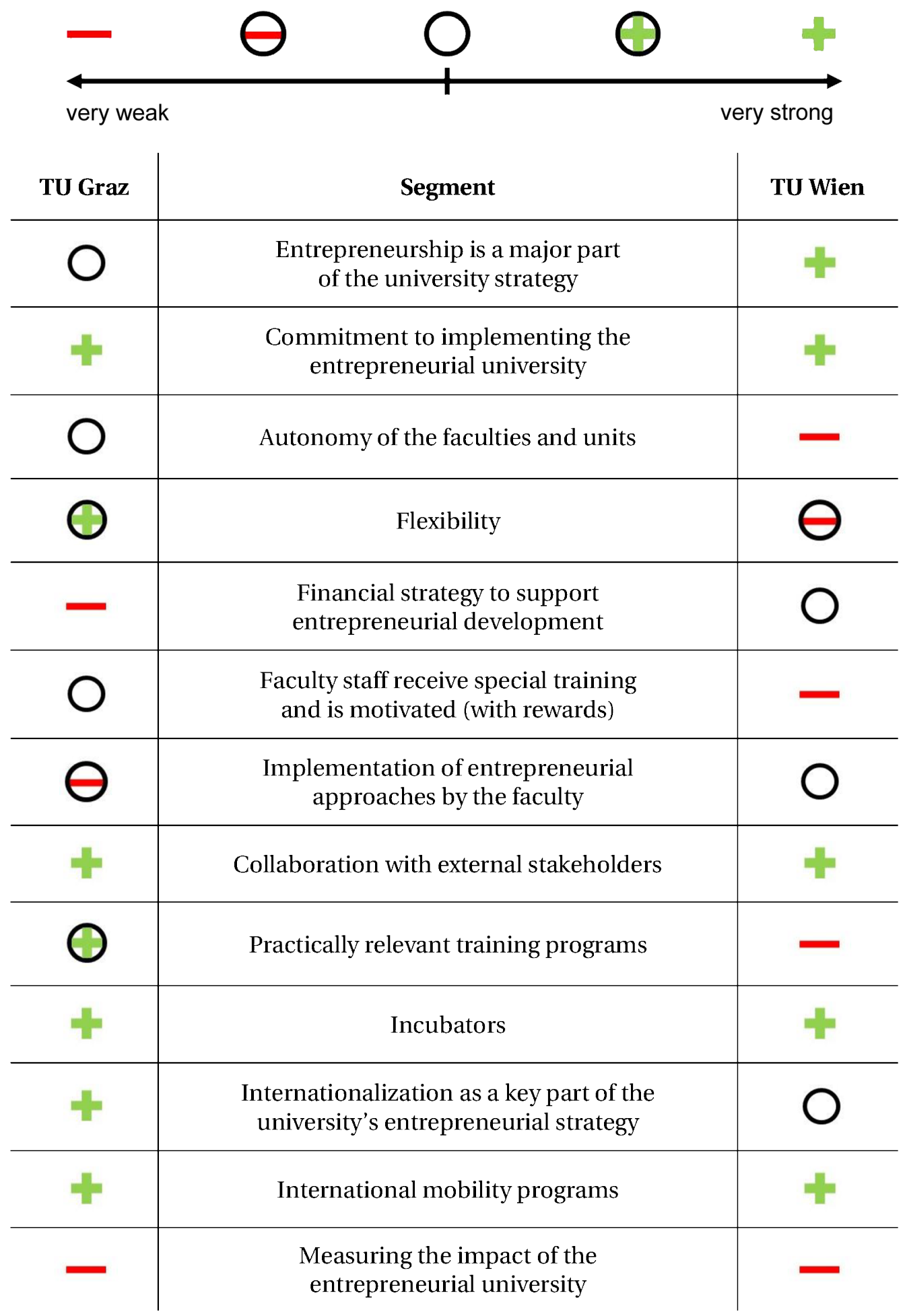




\title{
The Concept of the Entrepreneurial University in Austria
}

\author{
Martin Sperrer, Christiana Müller, and Julia Soos
}

The framework answers also reveal that, unlike TU Wien, TU Graz lacks a specific finance support strategy for entrepreneurial development, but it offers proportionally more of its funding for staff and students to support entrepreneurial activities. Thus, TU Graz may be putting greater emphasis on motivating its employees to "live" the model of the entrepreneurial university. But again, both universities still have room for improvement in this area.

The results also show that the universities have developed excellent relationships with external stakeholders and incubators. For example, both universities participate in the Austrian AplusB (Academia plus Business) incubator network that works closely with the higher-education sector and includes seven sites near the different universities. This network provides launch support to startups that already have a business idea (AplusB, 2016).

However, the results also reveal shortcomings in essential areas such as idea creation, implementation of an entrepreneurial spirit, and in provision of an entrepreneurial education in general. Both universities performed badly in terms of measuring the impact of their entrepreneurial programs. Thus, the impact of entrepreneurial teaching and learning activities are not assessed.

\section{Discussion and Conclusion}

In terms of fostering an entrepreneurial spirit and promoting entrepreneurship, the TU Austria has to make much greater efforts. By implementing mentoring systems, open spaces within incubators, and knowledge transfer centres, a network between institutions and organizations involved in the startup scene can be established. All universities of the TU Austria are already part of such networks, which are useful on the way becoming an entrepreneurial university. Nevertheless, the encouragement of an entrepreneurial spirit on the entire university campus should be an equal goal. Such an entrepreneurial spirit is helpful for students in identifying opportunities for personal growth and starting their own business as a further career opportunity (Volkman et al., 2009). The implementation of such a campus-wide spirit also has obstacles: not all students take courses in entrepreneurship and there may be a lack of entrepreneurial experience among faculty members. Furthermore, traditional (lecture-based) methods of education are not "state of the art" in entrepreneurial education. Students need access to broad opportunities for entrepreneurial education that are intensively promoted.
To further encourage the development of entrepreneurial mindsets in young people, the education system in Austria should implement entrepreneurship education tools at a much earlier stage in the education process of students. Currently, tools for entrepreneurial education and promotion of their availability starts predominantly at the master's level.

Universities in Austria should also encourage contests and friendly competitions. For example, in the United Kingdom, the National Centre for Entrepreneurship in Education launched the "Entrepreneurial University of the Year" program in cooperation with the Times Higher Education (Hannon, 2013). Another possibility is to start a student's club like the Cambridge University Technology and Enterprise Club (CUTEC) in Cambridge. This is a startup café that offers traineeships, promotes entrepreneurship at the university campus, and supports entrepreneurial campaigns and research (Hofer et al., 2010). To achieve even greater awareness of entrepreneurship among the students, interesting awards and prizes such as an exclusive party for the winning university could be offered.

Finally, it can be said that the model of the entrepreneurial university is already implemented in some parts of the TU Austria and is not just a vision of the future. Good cooperation with companies and with the Austrian AplusB incubator network are examples of the model is taking hold. Further entrepreneurial activities are being undertaken in the three universities of the TU Austria. For example, the TU Graz offers the course "Gründungsgarage", where students with a startup idea receive personal coaching from experts and participate in several workshops on business plans, business models, etc. On the way to becoming an entrepreneurial university, the TU Graz started an initiative together with the University of Graz to complement each other's efforts in becoming an entrepreneurial university.

\section{Acknowledgements}

An earlier version of this article was presented at the 2016 ISPIM Innovation Conference in Porto, Portugal, June 19-22. ISPIM (ispim.org) - the International Society for Professional Innovation Management - is a network of researchers, industrialists, consultants, and public bodies who share an interest in innovation management. 


\section{The Concept of the Entrepreneurial University in Austria}

\section{Martin Sperrer, Christiana Müller, and Julia Soos}

\section{About the Authors}

Martin Sperrer is a graduate student in Production Science and Management at the Nanyang Technology University in Singapore and Graz University of Technology (TU Graz) in Austria. He holds a Bachelor's degree in Industrial Engineering and Management, also from Graz University of Technology. His key research interests focus on technical processes and entrepreneurship.

Christiana Müller is an Assistant Professor at the Institute of General Management and Organization at the Graz University of Technology (TU Graz) in Austria. She holds a PhD in Techno-Economics and a Master's degree in Software Development and Business Management, both from TU Graz. The focus of her PhD was on the flexibility of business models, in particular which parts of the business model have to be flexible and which capabilities are therefore needed. Her current research topics span the area of technology-oriented business model innovation, both in established and start-up companies. She recently started a study to elaborate the influence of advancements in digitalization on business model development.

Julia Soos is a PhD candidate at the Graz University of Technology (TU Graz) in Austria, where she also holds a Master's degree in Industrial Engineering and Management. She has work experience as a business consultant covering diverse industries, with a focus on marketing, customer relationship management, and process management. Her current research interests lie in competence development for entrepreneurs in high-technology industries and the concept of the entrepreneurial university.

\section{References}

Alexander, A. T., Miller, K., \& Fielding, S. 2015. Open for Business: Universities, Entrepreneurial Academics and Open Innovation. International Journal of Innovation Management, 19 (6): 1540013. http://dx.doi.org/10.1142/S1363919615400137

AplusB. 2016. Das AplusB Programm. Zentrum für Angewandte Technologie (Center for Applied Technology). Accessed February 1, 2016:

http://www.zat.co.at/de/2696/

BMWFM. 2015. Land der Gründer - Auf dem Weg zum gründerfreundlichsten Land Europas. Vienna: Bundesministerium für Wissenschaft, Forschung und Wirtschaft (BMWFM) (Federal Ministry of Science, Research and Economy).

Daxner, F., \& Kailer, N. 2009. Gründungspotential und -aktivitäten von Studierenden technisch-naturwissenschaftlicher Studiengänge an Österreichischen Hochschulen. Ergebnisse einer Sonderauswertung. Linz, Austria: Johannes Kepler University (JKU).

EIT. 2016. EIT at a Glance. European Institute of Innovation \& Technology (EIT). Accessed September 1, 2016:

https://eit.europa.eu/eit-community/eit-glance

European Commission. 2008. Entrepreneurship in Higher Education, Especially within Non-Business Studies: Final Report of the Expert Group. Brussels: European Commission Directorate-General for Enterprise and Industry.

European Commission. 2011. HEInnovate: A Self-Assessment Tool for Innovation and Entrepreneurship. European Commission. Accessed September 1, 2016:

http://ec.europa.eu/education/tools/heinnovate_en.htm

Etzkowitz, H., Ranga, M., Brenner, M., Guarany, L., Maculan, A-M., \& Kneller, R. 2008. Pathways to the Entrepreneurial University: Towards a Global Convergence. Science and Public Policy, 35(9): 681-695.

http://dx.doi.org/10.3152/030234208X389701

Etzkowitz, H., Webster, A., Gebhardt, C., \& Cantisano, R. T. B. 2000. The Future of the University and the University of the Future: Evolution of Ivory Tower to Entrepreneurial Paradigm. Research Policy, 29(2): 313-330. http://dx.doi.org/10.1016/S0048-7333(99)00069-4

Fayolle, A., \& Redford, D. T. 2015. Introduction: Towards More Entrepreneurial Universities - Myth or Reality? In A. Fayolle \& D. T. Redford (Eds.), Handbook on the Entrepreneurial University: 1-8. Cheltenham: Edward Elgar Publishing Limited.

Gibb, A. A., \& Haskins, G. 2014. The University of the Future: An Entrepreneurial Stakeholder Learning Organization? In A. Fayolle \& D. T. Redford (Eds.), Handbook on the Entrepreneurial University: 25-63. Cheltenham: Edward Elgar Publishing Limited.

Hannon, D. P. 2013. Why is the Entrepreneurial University Important? Journal of Innovation Management, 1(2): 10-17.

Hofer, A.-R., Potter, J., Fayolle, A., Gulbrandsen, M., Hannon, P., Harding, R., Lindholm Dahlstrand, A., \& Phan, P. H. 2010. From Strategy to Practice in University Entrepreneurship Support: Strengthening Entrepreneurship and Local Economic Development in Eastern Germany: Youth, Entrepreneurship and Innovation. OECD Local Economic and Employment Development (LEED) Working Papers. Paris: OECD Publishing. http://dx.doi.org/10.1787/5km7rq1xvnxp-en 


\section{The Concept of the Entrepreneurial University in Austria}

\section{Martin Sperrer, Christiana Müller, and Julia Soos}

Krimsky, S., Ennis, J. G., \& Weissman, R. 1991. Academic-Corporate Ties in Biotechnology: A Quantitative Study. Science, Technology, \& Human Values, 16(3): 275-287.

http://dx.doi.org/10.1177/016224399101600301

Kulicke, M., \& Görisch, J. 2003. Welche Bedeutung haben Hochschulen für das regionale Gründungsgeschehen? - Zur Qualifizierungsfunktion von Hochschulen für technologieorientierte Gründungen. In K. Koschatzky (Ed.) Innovative Impulse für die Region - Aktuelle Tendenzen und Entwicklungsstrategien: 169-193. Stuttgart.

OECD. 2012. A Guiding Framework for Entrepreneurial Universities. OECD and the European Commission.

O'Shea, R. P., Allen, T. J., Morse, K. P., O'Gorman, C., \& Roche, F. 2007. Delineating the Anatomy of an Entrepreneurial University: The Massachusetts Institute of Technology Experience. $R \& D$ Management, 37(1): 1-16.

http://dx.doi.org/10.1111/j.1467-9310.2007.00454.x

Roberts, E. B., Murray, F., \& Kim, J. D. 2015. Entrepreneurship and Innovation at MIT: Continuing Global Growth and Impact. Cambridge, MA: MIT Sloan School of Management. http://entrepreneurship.mit.edu/wp-content/uploads/MITEntrepreneurship-Innovation-Impact-Report-2015.pdf

Singer, S., Amorós, J. E., \& Moska. D. 2014. Global Entrepreneurship Monitor: Global Report. London: Global Entrepreneurship Research Association.

Volkmann, C. 2009. Entrepreneurship in Higher Education: Educating the Next Wave of Entrepreneurs - Unlocking Entrepreneurial Capabilities to Meet the Global Challenges of the 21st Century. Geneva: World Economic Forum (WEF) 2009.

Citation: Sperrer, M., Müller, C., \& Soos, J. 2016. The

Concept of the Entrepreneurial University Applied to

Universities of Technology In Austria: Already Reality or

a Vision of the Future? Technology Innovation

Management Review, 6(10): 37-44.

http://timreview.ca/article/1026

Keywords: entrepreneurship, TU Austria,

entrepreneurial university, HEInnovate framework,

triple helix, entrepreneurial spirit, TU Graz, TU Wien 